\title{
Theorising knowledge practices: a missing piece of the educational technology puzzle
}

\author{
Sarah Howard ${ }^{\mathrm{a} *}$ and Karl Maton ${ }^{\mathrm{b}}$ \\ ${ }^{a}$ Faculty of Education, University of Wollongong, Wollongong, Australia; ${ }^{b}$ Faculty of Arts \\ and Social Sciences, University of Sydney, Sydney, Australia
}

(Received 7 February 2011; final version received 12 September 2011)

\begin{abstract}
Educational technology research has been characterised as lacking theoretical frameworks that can enable cumulative knowledge-building across the field. This article explores the value of Legitimation Code Theory (LCT) for addressing these issues by discussing research into the key question of integration of information and communication technologies in education. Specifically, it shows how LCT enables the theorisation of knowledge practices, the basis of education but undertheorised by existing research. Drawing on a major study of a technological initiative in all state secondary schools in New South Wales, Australia, the article illustratively uses one dimension of LCT to compare the organising principles underlying the initiative with those underlying the key subjects of mathematics and English. Analysis suggests that a 'code clash' with mathematics and a 'code match' with English might help explain their different patterns of integration of information and communication technologies. It also demonstrates how LCT can be utilised with multiple methods, enabling the integration of research into a wide range of educational topics and thereby contributing towards building knowledge across the field.
\end{abstract}

Keywords: technology integration; Legitimation Code Theory; specialisation; knowledge practices; theory; secondary schooling; subject areas

... there is nothing so practical as a good theory. (Lewin 1951, 169)

\section{Introduction}

That research into educational technology is undertheorised has become like the proverbial elephant in the room: most people know it is there but life goes on as if it is not. Yet, the paucity of powerful theory represents an elephantine obstacle to progress in the field. As social realist sociology of knowledge reveals, intellectual fields that lack explicit, powerful theoretical frameworks capable of underpinning empirical research tend towards repetition, fragmentation and segmentalism (Maton and Moore 2010). Similarly, educational technology research is often characterised by limited cumulative knowledge-building and isolation from other areas of educational research (Czerniewicz 2008, 2010). This article explores the value for educational technology research of a framework that is being adopted across a

*Corresponding author. Email: sahoward@uow.edu.au 
range of disciplines: Legitimation Code Theory (LCT). LCT is a practical theory; it offers an array of concepts that are used in empirical research to provide explanations of substantive problems. It also helps overcome segmentalism by enabling research of a wide variety of issues using a range of methods. Moreover, as we shall discuss, LCT brings to light an issue often neglected by educational technology research: knowledge. Of course, LCT is not a Grand Unified Theory, but rather helps reveal a missing piece of the puzzle and in ways that enable knowledge-building in research.

To illustrate its value for educational technology, our substantive focus reflects one of the most significant issues facing the field: integration. Access to information and communication technologies (ICTs) in schools has risen dramatically in recent years, but the integration of these tools in teaching and learning has not shown consistent comparable gains (Hew and Brush 2007). Research reveals remarkable variation in the use of ICTs, with some subject areas consistently showing more integration of technology than others (Hennessy, Ruthven, and Brindley 2005; Howard 2009). In this article we illustrate the value of LCT for exploring the question of why ICTs are integrated differently across the disciplinary map.

We begin by highlighting how existing studies of integration delineate a range of factors but typically obscure the structuring of knowledge and, where knowledge is addressed, often remain at the surface level of empirical descriptions rather than analysing the principles underlying practices. Secondly, the notion of 'specialisation codes', one dimension of LCT, is introduced to provide a means of analysing one set of these organising principles. Thirdly, the usefulness of this framework is illustrated through discussion of a major, mixed-method study of a large-scale integration initiative, the Digital Education Revolution in New South Wales (DER-NSW), Australia, focusing on the key subjects of mathematics and English. Using documentary, quantitative and qualitative data, the underlying principles of their knowledge practices are analysed and compared with those aimed for by the initiative. The analysis suggests that the policy aims exhibit a 'code clash' with the knowledge practices dominating mathematics and a 'code match' with many of those of English. We conclude by discussing how LCT not only helps explain integration of educational technology by highlighting the role played by knowledge practices, but also offers a means of enabling integration of education technology research itself.

\section{Knowledge-blindness in educational research}

It is the production, recontextualisation, teaching and learning of knowledge that makes education a distinctive social field of practice. However, as a growing number of scholars are arguing, knowledge has often been obscured by educational research thanks to a false dichotomy that creates 'knowledge-blindness' (Maton, forthcoming). This false dichotomy between studying either knowing or knowers results partly from the ways psychology and sociology have been recontextualised into educational research over the past 40 years (Freebody, Maton, and Martin 2008). On the one hand, psychologically-informed approaches typically focus on processes of learning and sideline differences between the forms of knowledge being learned. 'Knowledge' tends to be viewed as that which is in people's minds, and 'learning' as comprising generic processes - the central focus is thus knowing. On the other hand, sociologically-informed approaches typically emphasise knowers. Since the 
early 1970s, various forms of social constructivism have dominated the field in the guise of the 'new sociology of education', standpoint theories, 'critical' theories, 'post-'theories, progressivism, constructivism, and so on. These have often taken the notion that 'knowledge is socially constructed' to mean that knowledge is nothing but a social construction that reflects the disguised interests of dominant interests. The key focus for research then becomes unmasking the social power underlying knowledge and the key question is 'Whose knowledge?' - a focus on knowers. A similar focus, although less explicitly political, can also be found in approaches that explore the nature of the communities engaged in knowledge practices. While usefully highlighting that knowledge or 'epistemic' issues are significant, their primary concern is with relations among knowers in such communities.

Studies of knowing and of knowers have, of course, contributed much to educational thinking and are highly significant. However, this false dichotomy limits the range of positions actors see as legitimate within educational research and, as a result, what remains largely missing is the study of knowledge itself. Moreover, such study can be mistakenly associated with essentialism and conservatism, as if analysing knowledge is in itself to essentialise specific forms of knowledge, rather than simply to reveal the ways they can themselves shape beliefs, actions and social relations of power.

Educational technology research has often been affected by knowledge-blindness. Focusing on the issue of integration, studies have typically aimed to develop a 'holistic' account of contextual factors influencing the degree and kinds of use of technology within classrooms (for example, Hew and Brush 2007; Mueller et al. 2008; Scheuermann and Pedró 2010). However, knowledge is overwhelmingly a missing factor from such accounts. For example, the international Second Information Technology in Education Study (SITES) 2006 (Law, Pelgrum, and Plomp 2008) is a large-scale, cross-national study that offers an explanatory model of factors shaping the use of ICTs for pedagogical purposes. As shown by Figure 1, the framework used by SITES studies (Plomp, Pelgrum, and Carstens 2009) identifies "teacher characteristics", "school factors", and "system and other external factors" as related to "pedagogical practices and ICT use". Although the portrayal of relations of influence among factors developed slightly during the studies, the structuring of educational knowledge remained unconsidered as an influence on integration of ICTs. Some surface-level 'knowledge' features are highlighted (such as 'curriculum goals') but the underlying principles of what is being taught and learned in classrooms remains outside the analysis. We should emphasise that highlighting this absence is not to dismiss such studies - they provide insight into a variety of factors affecting integration. Rather, it is simply to highlight a missing piece of the puzzle.

The SITES studies raise a second problem: where aspects of knowledge are addressed by educational technology research, they remain undertheorised, a kind of 'knowledge short-sightedness'. This typically takes the form of models that list what knowledge is of, but which do not then analyse the forms taken by that knowledge. A well-known example is the Technological Pedagogical Content Knowledge (TPCK) model (Koehler, Mishra, and Yahya 2007; Mishra and Koehler 2006), which extends Shulman's (1987) description of teachers as bringing together pedagogical and content knowledge in their teaching practices. The TPCK model argues that teachers' understandings of technology need to be related to their understandings of pedagogy and content. TPCK is valuable in highlighting knowledge as 


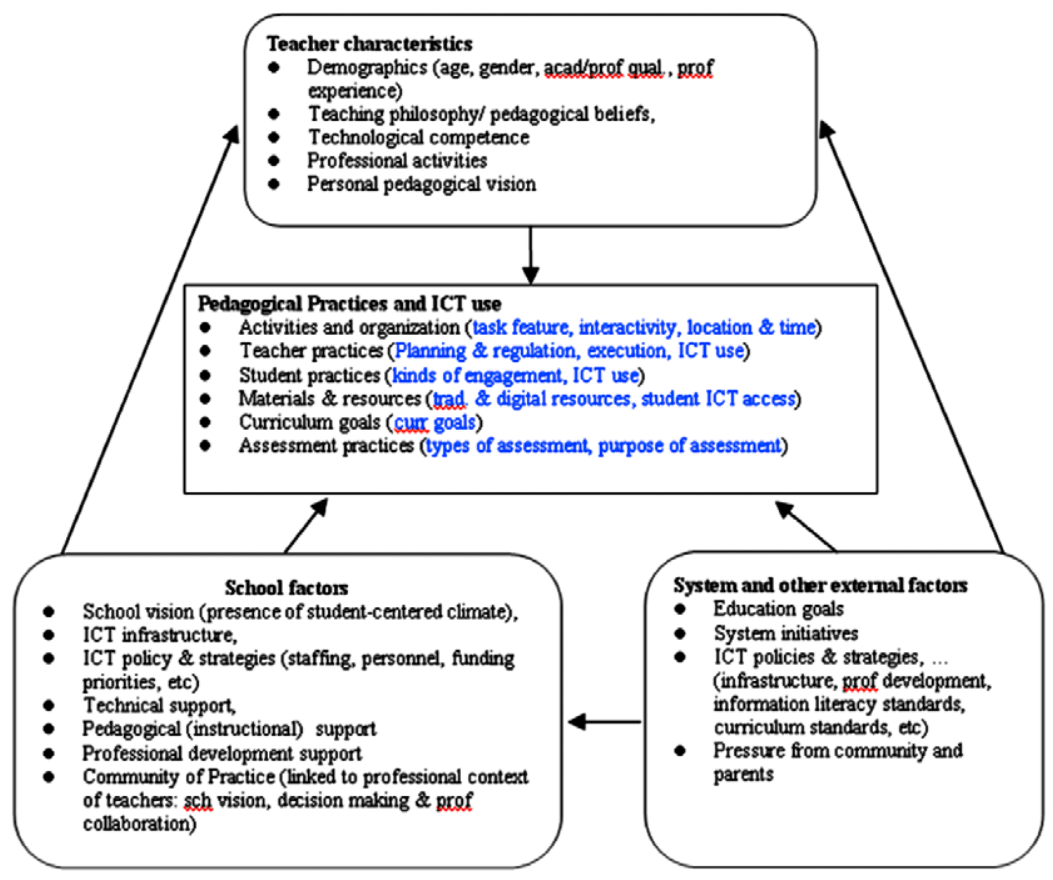

Figure 1. Analytic framework for SITES.

Source: International Association for the Evaluation of Educational Achievement (2005).

significant and is proving useful in teacher training (for example, Angeli and Valanides 2009). However, while highlighting different contents or foci of knowledge, this does not provide a means of theorising the forms that knowledge takes, whether its three constituent kinds (the three circles in Figure 2), their hybrids (the three elliptical unions) or TPCK itself (the centre). Such a means of conceptualising their underlying principles is required to show the forms taken by technological, pedagogical and content knowledge and how these may change when brought together in various combinations and when enacted in different contexts.

Models such as TPCK and SITES thus offer exploratory and insightful first steps but need development to become explanatory theoretical frameworks. They highlight factors and relations to be explored but, without a conceptual framework for systematically analysing similarities, variations and differences both within a set of factors (such as 'technological knowledge') and between factors (such as 'TPCK'), studies using these models remain at the level of empirical differences and locked into their contexts of study. As Mishra and Koelher state when defining TPCK, if the factors shaping educational technology are seen as "contextually bound", then "it is difficult to study cause and effect when teachers, classrooms, politics, and curriculum goals vary from case to case" $(2006,108)$. This problematises the capacity of studies to build on other research into different contexts by segmenting the field into a series of context-specific studies. What is required, then, both for understanding the integration of ICTs and for helping to build an integrated field of research, is a means of not only seeing knowledge but also moving beyond empirical descriptions of knowledge practices to analyse the principles underlying those practices. 


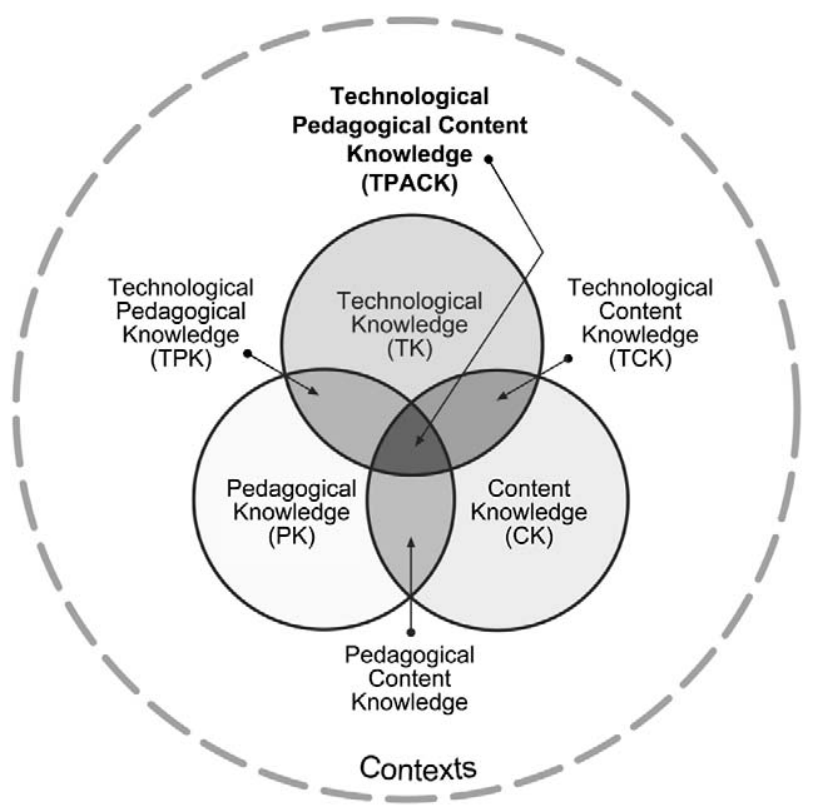

Figure 2. The TPCK model.

Source: Koehler and Mishra (2010).

As Moore and Maton $(2001,154)$ argue, "describing what is obscured by a blindspot is extremely difficult, for what you are trying to point to simply cannot be seen through the current lens". This is made more difficult in fields with a wide diversity of models and approaches. Clearly, detailed discussion of every lens to be found in educational technology research is beyond the scope of this article. Moreover, reviewing the field is not our intention. Existing reviews - such as Czerniewicz $(2008,2010)$ on educational technology and Muller (2000), Young (2008), Moore (2009) and Maton and Moore (2010) on educational research - provide more extensive discussions of knowledge-blindness across a range of approaches. Nonetheless, the above illustrates how a particular piece of the puzzle is often missing. In order to overcome the blindspot, the rest of this article offers a new lens and illustrates what it makes visible.

\section{Seeing and analysing knowledge: Legitimation Code Theory}

LCT is a central conceptual framework of social realism, a broad 'school of thought' that offers a means of moving beyond social constructionism (Maton and Moore 2010). Social realism shows not only that knowledge is socially constructed, dynamic and the focus of ongoing struggles among historically and socially located actors with different resources. It also reveals how the forms taken by knowledge have their own properties, powers and tendencies and help shape those ongoing struggles. Knowledge is not only social, it is also real, in the sense of having effects. For example, some forms of knowledge are more capable of cumulative knowledge-building than others, and some are more suited to the learning needs of some social groups than others. 
LCT analyses the bases of achievement underlying social contexts as a means of understanding practice (Maton 2000, 2007, 2010, forthcoming). It views the practices and beliefs of agents as embodying 'languages of legitimation': messages as to what should be the dominant basis of achievement. The organising principles underlying these messages are conceptualised as 'legitimation codes'. These codes can be analysed along a number of dimensions using a sophisticated conceptual toolkit addressing a range of issues. One of these dimensions is 'Specialisation' or what makes someone or something different, special and worthy of distinction. This dimension highlights that every practice, belief or knowledge claim is about or oriented towards something and by someone. One can, therefore, analytically distinguish: epistemic relations (ER) between practices and their object or focus; and social relations (SR) between practices and their subject, author or actor. Put briefly, each relation may be more strongly or weakly emphasised in practices and beliefs, and these two relative strengths together give the specialisation code of legitimation. These continua of strengths can be visualised as $x$ and $y$ axes of a Cartesian plane in which one can identify four principal modalities (Figure 3):

- a knowledge code, where possession of specialised knowledge, principles or procedures are emphasised as the basis of achievement, and the attributes of actors are downplayed;

- a knower code, where specialist knowledge is less significant and instead the attributes of actors as knowers are emphasised as the measure of achievement, whether these attributes are viewed as born (e.g. 'natural talent'), cultivated (e.g. artistic gaze or 'taste') or socially based (e.g. gendered gaze in feminist standpoint theory);

- an elite code, where legitimacy is based on both possessing specialist knowledge and being the right kind of knower (the term 'elite' does not indicate social exclusivity, but rather the significance of possessing both legitimate knowledge and legitimate dispositions); and

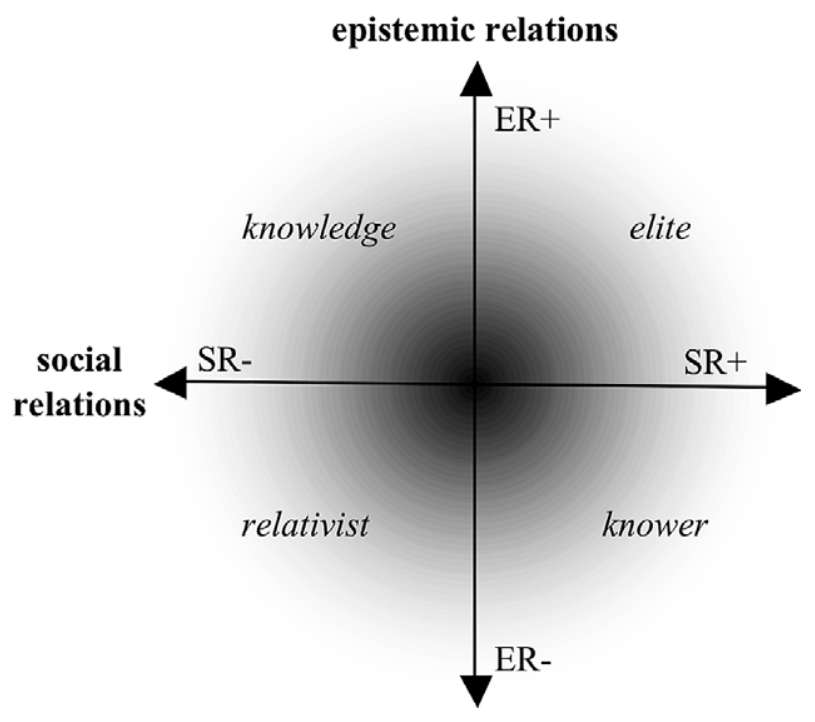

Figure 3. Specialization codes of legitimation.

Source: Maton $(2007,97)$. 
- a relativist code, where legitimacy is determined by neither specialist knowledge nor knower attributes - a form of 'anything goes'.

The code describes the 'rules of the game' or dominant basis of success of a social context; in the four specialisation codes, what matters is 'what you know' (knowledge code), 'the kind of knower you are' (knower code), both (elite code) or neither (relativist code). A specific code may dominate as the (typically unwritten) rules of the game, but may not be transparent, universal or uncontested. Not everyone may recognise and/or be able to realise what is required, there is typically more than one code present, and there are likely to be struggles among actors over which code is dominant. One can thus talk of degrees of 'code clash' and 'code match', such as between: learners' ways of thinking and being and the educational context (for example, Chen, Maton, and Bennett 2011); different approaches within an intellectual field (for example, Carvalho, Dong, and Maton 2009); or the goals of educational policies and the ways of working of different subject areas (see below). For example, a study of Chinese students studying online at an Australian university reveals how knowledge-code dispositions brought by these students from their past educational experiences clashes with the knower code characterising constructivist forms of online learning, resulting in anxiety, alienation, depression and disengagement among students (Chen, Maton, and Bennett 2011). As well as clashes, the dominant code may also change, such as between subject areas, classrooms and stages of a curriculum. These 'code shifts' effectively change the rules of the game. For example, the school music curriculum in English schools involves shifts from a knower code at primary schooling to a knowledge code during the early years of secondary schooling, and then towards an elite code for the GCSE qualification (Lamont and Maton 2008, 2010).

By conceptualising the principles underlying practices, the dimensions of LCT (of which we have only briefly introduced one) may be used across diverse research agendas. ${ }^{1}$ As a growing number of studies are showing (Maton, Hood, and Shay, forthcoming), each dimension of LCT can be used to analyse:

- all kinds of practices - curriculum, pedagogy, evaluation, beliefs, classroom interactions, and so forth;

- at different levels of analysis - a national curriculum, school, subject area, classroom, and so on, as well as beyond formal education;

- in conjunction with other approaches, such as systemic functional linguistics; and

- using a range of methods, including documentary analysis, quantitative surveys and qualitative interviews.

LCT thereby provides the possibility of an integrating analysis of ICT integration. The framework allows educational technology to be brought into relation with other dimensions of teaching and learning, and enables comparison of different contexts and analysis of change over time without becoming lost in empirical differences. The theory is also suggestive. The notion of degrees of code clash or match suggests one issue affecting integration could be that the bases of achievement underlying technology practices being enacted match those of some subject areas (and within them, some knowledge practices) more closely than others. LCT thereby offers a basis for building a theoretically-informed, empirically-based 
approach bringing together quantitative and qualitative studies of a range of educational contexts. To illustrate how this framework can be used in empirical research, we shall now briefly discuss a large-scale study of ICT use in education.

\section{Analysing the Digital Education Revolution}

LCT(Specialisation) is the central framework for a major evaluation of the Digital Education Revolution in New South Wales (DER-NSW), part of an Australian federal initiative to provide students and teachers with access to digital technology. In New South Wales, the DER involves providing a laptop for every student during Years 9-12. The NSW Department of Education and Training is conducting a three-year (2010-2012) evaluation of this programme in all state government secondary schools. In this article we draw on data collected during 2010, which combined quantitative and qualitative methods in two main phases.

Phase 1 comprised two online student questionnaires, of which each student completed either StuA $(n=14,299)$ or StuB $(n=13,513)$, and one online teacher questionnaire, $\operatorname{TrA}(n=4,604)$. StuA and StuB were randomly assigned to all Year 9 students based on their school and completed during their laptop orientation; TrA was distributed to all teachers in NSW senior schools (Years 9-12).

Phase 2 comprised case studies of four schools, selected according to student and teacher participation in Phase 1. Data collection for each case study included documentary analysis of school, state and federal policy and curriculum documents, separate focus groups of teachers and of Year 9 students ( $n=7-8$, for each group), and interviews (teachers, $n=3-4$; students, $n=3-4$ ).

Both phases explored a wider range of factors concerning students' and teachers' ICT use and beliefs than can be discussed in this article. Following our aim of illustrating the value of theorising knowledge practices for understanding integration, we limit our focus here to relations between practices sought by the DERNSW and those of subject areas. The specialisation code of the DER was explored through thematic documentary analysis of policy guidelines, professional development online modules and curriculum documents (e.g. NSW Year 9 syllabus). The specialisation codes of major subject areas were ascertained in student and teacher questionnaires by adapting an item developed for studies of subject choice in the United Kingdom (Lamont and Maton 2008; Maton 2007). As illustrated in Figure 4, the item addresses the significance of epistemic relations ('knowledge and skills') and social relations ("natural talent' and 'experience and a "feel"') for achievement in each subject. Students were asked the question for seven major subject areas (mathematics, English, science, history, geography, music and visual arts) as well as technology; teachers were asked about technology and their primary curriculum

How important are the following things for being good at Maths?

\begin{tabular}{|l|c|c|c|c|}
\hline & $\begin{array}{c}\text { Not } \\
\text { at all }\end{array}$ & $\begin{array}{c}\text { Not very } \\
\text { important }\end{array}$ & Important & $\begin{array}{c}\text { Very } \\
\text { important }\end{array}$ \\
\hline Having natural talent at Maths. & $\bigcirc$ & $\bigcirc$ & $\bigcirc$ & $\bigcirc$ \\
\hline Learning knowledge and skills in Maths. & $\bigcirc$ & $\bigcirc$ & $\bigcirc$ & $\bigcirc$ \\
\hline Getting experience or a 'feel' for Maths. & $\bigcirc$ & $\bigcirc$ & $\bigcirc$ & $\bigcirc$ \\
\hline
\end{tabular}

Figure 4. Generic version of the specialisation code item. 


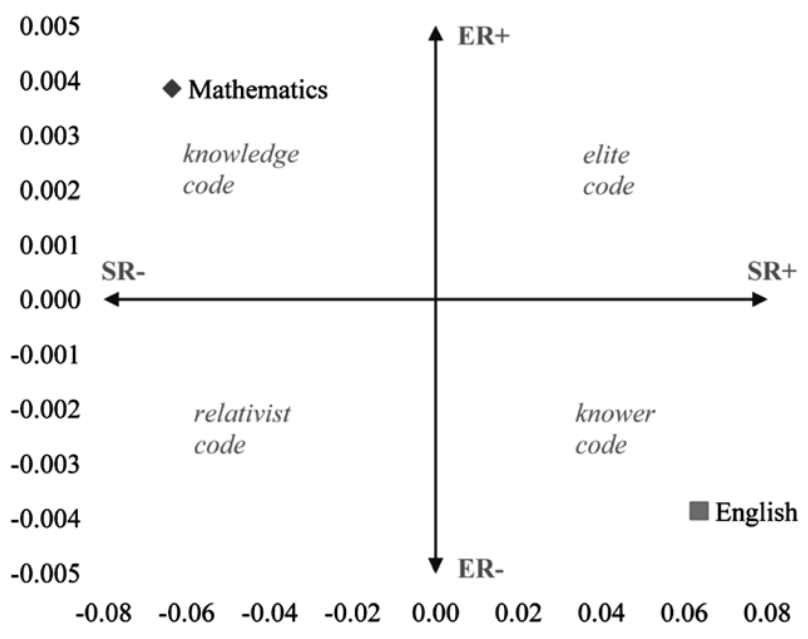

Figure 5. Students' perceptions of bases of achievement of mathematics and English.

area. Responses were converted into specialisation codes by calculating the relative strengths of the epistemic and social relations for each subject relative to those of all other subjects, where the means of all subjects provide each axis of the Specialisation plane and the scores of each subject provides its $x-y$ location (see Figures 5 and 6). The item was also adapted and expanded for interviews and focus groups in Phase 2 case studies, using a combined episodic and critical incident method (Flick 2006) that probed for examples and compared bases of achievement for a range of subjects, and which was analysed using a thematic coding method.

Drawing from the evaluation data, we shall now, first, code the DER-NSW policy initiative, then subject areas, focusing on English and mathematics, before bringing these together to illustratively discuss how clashes and matches between the codes may help shed light on differences in the integration of ICTs in classrooms.

\section{Coding the revolution}

The DER is an Australian federal initiative promoting the innovative uses of technologies to 'enable school users to discover, access and share collaborative education materials and information' (Department of Education Employment and Workplace Relations 2008). Central to its implementation in NSW is an expectation that ICTs (specifically, laptops) will create a shift in teaching and learning practices. This is exemplified by an online module provided by the professional development unit of the NSW Department of Education and Training to help principals and teachers develop 'the pedagogy that is required for this change' (Professional Learning and Leadership Development Directorate [PLLDD] 2010a). In the introductory video on pedagogy, existing forms are dismissed as nineteenth-century relics inappropriate to "a digital age or the world in which young people live". In contrast, "twenty-first century pedagogy" is said to require a change in the "DNA" of practices, one representing a moral imperative: "What is going to happen if we don't get the new DNA? We are going to continue to condemn future generations of teachers, because we have not changed the fundamental building blocks of what we are on about" (PLLDD 2010a). Similarly, a module on "Change" (PLLDD 2010b) provides a video 
listing a series of attributes of "teachers today", including that they "embrace change and redefine education" and "are fluent in technology tools".

The anticipated change is from an instructivist emphasis on knowledge to a constructivist emphasis on the knower. The purportedly outdated pedagogy is focused on the "transmission of knowledge", whereas in the new pedagogy "we are co-constructors of learning and co-constructors of knowledge" (PLLDD 2010a). Noticeably absent from professional development guidance is knowledge (unless negatively coupled with "transmission") or differences among subject areas. Epistemic relations concerning what is being taught and learned are, therefore, downplayed. In contrast, teachers and students as knowers are the central focus: social relations are emphasised. The attributes of "teachers today" focus on personal qualities and capacities, ICTs are viewed as enabling students' personal creativity and expression, and teachers are expected to adopt practices associated with 'studentcentred learning' that claim to view learners as already-legitimate knowers. Policy guidance in the initiative thereby expects the provision of laptops to lead not only to their integration but also to the instigation of knower-code practices across the curriculum.

\section{Coding subjects}

The DER-NSW treats subject areas as homogeneous and forms of knowledge as neutral media for technologically-driven pedagogic change. However, findings from questionnaires, focus groups and interviews suggest otherwise: there are a range of different specialisation codes underlying subjects. Here, for illustration, we shall focus on the key subjects of mathematics and English, targets of the Australian federal 'National Assessment Program - Literacy and Numeracy' and gateway disciplines to the sciences and humanities. Figures 5 and 6 present the quantitative findings on student and teacher perceptions of the bases of achievement of these subjects. Both groups characterise mathematics as a knowledge code and English as a knower code, reflecting cognate research on these fields (for example, Christie and Macken-Horarik 2011; Muijs et al. 2005).

Questionnaire results also reveal differences in teachers' use of ICTs, with participating mathematics teachers $(n=522)$ reporting less of a tendency to use ICTs in their teaching $(M=5.68, S D=2.27)$ than English teachers $(n=568 ; M=6.17, S D$ $=2.00 ; t(1018)=3.61, p<.001){ }^{2}$ This difference was not, however, reflected in their use of computers outside school (Mathematics, $M=7.51, S D=1.00$; English, $M=7.49, S D=1.00 ; t(1206)=-.32, p=.747)$, nor in their general computer use at school (Mathematics, $M=7.80, S D=.57$; English, $M=7.82, S D=.57 ; t(1029)=$ $.77, p=.404)$; subject areas would appear to matter. Similarly, when asked if they felt their classroom practices were becoming 'more student-centred' 3 as a result of DER-NSW, mathematics teachers reported $(M=2.63, S D=.70)$ less agreement than English teachers $(M=2.86, S D=.79 ; t(881)=3.78, p<.001)$. These disciplinary variations were reflected by students' responses on questionnaire $\operatorname{StuB}(n=13,513)$, which indicated technology was "Not very important" in mathematics ${ }^{4}(M=2.76$, $S D=.86)$ but "Important" in English $(M=3.01, S D=.75)$.

These differences in both the integration of ICTs and specialisation codes for these subjects raise the possibility that lower usage in mathematics (knowledge code) and greater degree of integration in English (knower code) reflect their respective code clash and code match with the knower-code aims of DER-NSW. To 


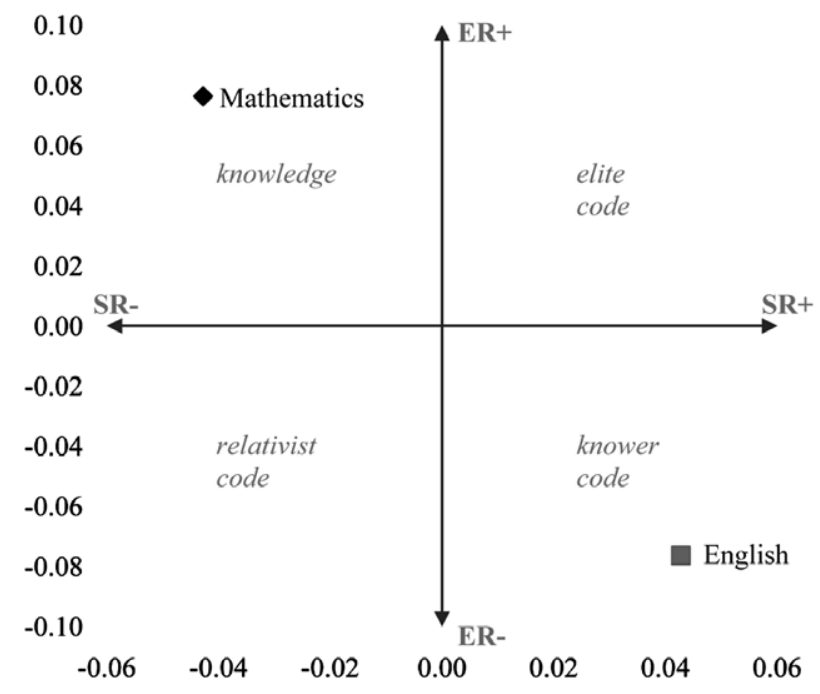

Figure 6. Teachers' perceptions of bases of achievement of mathematics and English.

explore this further we now turn to briefly discuss illustrative findings of teacher interviews and focus groups in each subject area.

\section{Code clashes and matches}

\section{Mathematics knowledge}

As mathematics teachers repeatedly declared in focus groups and interviews: "Maths is about practice, practice, practice" (School 1, Teacher 1), "you've got to practice that same thing over and over again" (School 4, Teacher 2). What was said to require practice was mathematical skills; teachers highlighted the significance of practising problems for homework, working through problems on the board in class, reviewing topics and assessing students' understanding. In short, teachers highlighted the knowledge needed for students to understand mathematics. In LCT terms, they emphasised epistemic relations as central to achievement, echoing the knowledge code characterising mathematics in teacher and student questionnaires. Importantly, their relatively low use of ICTs in the classroom did not reflect an antipathy towards technology per se; mathematics teachers were generally positive towards using technology in teaching and learning. Rather, it was the value for learning mathematics of the knower-code practices often associated with ICTs that was viewed with scepticism. For example, one teacher described exploration and research tasks using the Internet as feasible but less useful for learning mathematics than for (knower-code) subjects such as English:

I suppose sometimes the world of the internet is a wonderful thing but we use it in a limited fashion in Maths ... I just don't think we use that or we need to use that as much as other subjects. I see other subjects using that as a great tool for their learning for English or history and so on. So I think for Maths, yeah, we're a little bit lower on the scale of usefulness. (School 1, Teacher 1)

Asked about using constructivist practices, another teacher paused for reflection before exclaiming "Oh! You mean the long way around!" (School 4, Teacher 2). 
That this perceived mismatch between the kinds of practices associated with the technological initiative and learning mathematics may reflect a code clash is further illustrated by the ways teachers adapted technology practices to suit the needs of their subject area. For example, teachers highlighted the value of teaching mathematical principles through spreadsheets (although this is required by the mathematics curriculum during Years 7-10) and often identified online 'drill and practice' sites and visualisation software (such as Geogebra and Geometers' Sketch Pad) as useful tools. Although, designed for discovery learning, teachers typically used visualisation resources as supplementary ways of teaching mathematical skills, such as graphing or using protractors:

in [the] Notebook, there's a few applications within that that we can measure angles and learn how to use the digital protractors and stuff like that. I find that I've got to actually have them physically using the hard, the real stuff because they're not taking those laptops into whatever [the test] - but ... it gives that point of view I guess, a different way to look at those same tools. (School 4, Teacher 2)

ICTs were thus used for knowledge-code practices, emphasising epistemic relations (knowledge, skills, principles, etc.) rather than social relations (learners' dispositions as shown for example by free expression).

In short, if technological practices were not viewed as valuable for learning the knowledge practices of mathematics, teachers did not use them or, when they did, they adapted resources to match the 'rules of the game' of the subject. Thus, one reason for relatively low integration in mathematics may be this code clash with the perceived knower code associated with educational technology and which reflects the aims of the DER-NSW.

\section{English knowers}

English offers a different story. In the questionnaire data, both teachers and students characterised English as a knower code, one based on "getting 'a feel" for the subject, or what LCT terms a "cultivated gaze" (Maton 2010). This was reflected in interviews, where teachers highlighted learners' dispositions, such as "a love of words, of language itself" and "the stimulation they get from imagery from the written word" (School 2, Teacher 4). Students were often portrayed as already legitimate knowers, and specialist knowledge they might need to learn was downplayed. This was mirrored by discussions of technological practices. Where mathematics teachers often used ICTs to provide different ways for students to learn mathematical skills, English teachers typically described ICTs as useful for providing different ways for students to express themselves. For example:

I think what I like about the laptops is that gives you a different medium for production ... things like creating your own posters and TV type advertisements, book trailers, things like that and so it's getting them to demonstrate their knowledge in different ways and I think that that's a good thing. (School 3, Teacher 1)

This match with the knower code often associated with ICTs was echoed by the more wide-ranging nature of discussions by English teachers of using ICTs and constructivist practices in classrooms; for example, one teacher enthused about blogging: 
It enables them to experiment, it makes it easier, they don't have to worry about their spelling anymore, which has it's bad side effects, but they don't have to worry about that, they can do spellcheck, they can experiment. (School 2, Teacher 4)

Enhancing students' experiences and discovery were thus, for many of the teachers, important for achievement in English and enabled by ICTs. However, as this quote illustrates, while English was characterised as a knower code overall, not every aspect of the subject is the same code. Significantly, teachers expressed concern about the value of ICTs for practices characterised by a knowledge code, such as learning the technical skills required for composition. Teachers often emphasised the importance of structure, spelling and grammar, and stated that ICTs were not only of limited value but could be actively deleterious to learning such skills. For example, one teacher described how students using laptops to write appeared to think they "eliminated the drafting process", failed to check their spelling or grammar, and so required more teaching of these skills (School 3, focus group).

The degree of integration of ICTs into the classroom was thereby related to the code underlying specific knowledge practices rather than to the subject per se. Thus, while mathematics and English may have different patterns of integration, the reasons are the same: teachers engaged with knower-code technological practices where these served knower-code pedagogic needs but viewed them as less valuable for learning specific skills and knowledge. English teachers expressed in interviews both enthusiasm for ICT-supported practices that enable personal expression (knower code) and concern over their effects on students' learning of skills required to master language and literature (knowledge code). For example, one teacher who set a PowerPoint presentation for her class captures this ambivalence well:

I wasn't 100 percent happy with the Powerpoint presentations they showed, I actually was happy with it, that they were working on their own to produce something. ... they're demonstrating what they're learning and they get a lot out of it. And they're showing it to their own peer groups, there's a purpose behind it, they get a kick out of seeing something that they've produced and you know, it is a really positive experience. (School 3, Teacher 1)

She was happy with the capacity of PowerPoint presentations to enhance students' experiences as knowers but, as she went on to elaborate, unhappy with the structure and content of the knowledge they presented.

In summary, teachers of English described a greater degree of integration of ICTs within their classrooms than teachers of mathematics, reflecting the code match between the subject's knower code and that often associated with educational technology, such as the DER-NSW initiative. Despite this difference, teachers in both subjects expressed a similar pattern of code-matching between technological and knowledge practices; and where these clashed, such as for learning spelling and grammar in English, they were less enthusiastic about using ICTs. The code underlying practices would thereby appear to help explain not only the different degrees of integration of subject areas but also the forms taken by uses of ICTs.

\section{Conclusion: LCT and integration}

We began this article by arguing that knowledge is a missing piece of the educational technology puzzle. Typically, models of the integration of ICTs in education 
either obscure the role played by knowledge or highlight, but do not theorise, knowledge and so remain at the level of empirical descriptions. One result for educational technology research is segmentalism, where studies are locked into the specificities of their objects of study, constraining the possibility of building knowledge in the field. LCT, we suggest, offers a conceptual framework that both: enables the role of knowledge to be brought into the picture alongside other factors highlighted by existing studies; and explores the principles underlying practices in ways that enable divergent objects of study, practices and contexts to be brought together.

Drawing on one dimension of LCT - Specialisation - we briefly discussed findings from a major study of DER-NSW, a large-scale Australian policy initiative, focusing on the different profiles of ICT use in the key subjects of mathematics and English. Analysis of the principles underlying these subject areas suggested that one reason for the relatively lower use of ICTs in mathematics may be a 'code clash' between its knowledge code and the knower code characterising the practices aimed for by the policy. Conversely, the greater degree of technological integration in English may reflect the 'code match' between those practices and the subject's knower code. Crucially, this is not to essentialise disciplines. As illustrated by the ambivalence of English teachers towards ICTs when discussing technical aspects of writing and the adoption by mathematics teachers of ICTs that enable practice of mathematical skills, it is the code underlying knowledge practices that matters rather than the subject area per se.

As well as highlighting the role played by knowledge practices in shaping integration of ICTs in classrooms, this analysis has implications for future directions of research. We should emphasise we are not advocating any specific code, denying the potential for ICTs to reshape knowledge practices, or arguing knowledge practices alone shape the use of ICTs. Rather, the approach suggests that future research should include exploring how to articulate the principles underlying technological and knowledge practices in order to negotiate code clashes and enable code matches. In educational technology research, ICTs have often been identified with constructivism and resources such as 'drill and practice' software have been denigrated as low-level and remedial (for example, Bottino 2004; Warschauer and Matuchniak 2010) or demonised as failing to support the co-construction of meaning (Scardamalia and Bereiter 2006). Analysing knowledge practices highlights that such claims essentialise ICTs as a knower code, ignore the desire of teachers for technological resources for knowledge-code pedagogy and the potential of ICTs to fulfil that desire, and fail to recognise that students engage in meaning-making in relations not only with other knowers but also with the knowledge they are students of. LCT can thereby help reveal how the tacit principles underlying educational technology research itself may be detrimental to greater integration of ICTs.

LCT may also help contribute to enabling greater integration within the intellectual field itself. The framework can be used to analyse diverse forms of data using quantitative, qualitative and documentary methods, enabling a wide range of factors to be integrated within a single analysis, and enabling different analyses to be related together. Where models such as SITES and TPCK offer a valuable list of factors to be addressed, LCT provides a means of analysing and relating those factors in ways that move beyond the specificities of each case. Its use in research on topics as diverse as nursing in higher education, physics, school English, music, museums and freemasonry, and its capacity to be employed in conjunction with 
other approaches is also helping research from across education to speak to one another. For both exploring and enabling integration, LCT is beginning to show (to twist Lewin) that there is nothing so good as a practical theory.

\section{Notes}

1. For many studies using LCT, see: http://www.legitimationcodetheory.com.

2. Teachers' technology use items were rated on an eight-point Likert-type scale from 'Never $=0$ ' to 'Many times a day $=8$ '.

3. The item was rated on a four-point Likert-type scale from 'Not at all $=1$ ' to 'Very important $=4$.

4. The item was rated on a four-point Likert-type scale from 'Strongly disagree $=1$ ' to 'Strongly agree $=4$ '.

\section{References}

Angeli, C., and N. Valanides. 2009. Epistemological and methodological issues for the conceptualization, development, and assessment of ICT-TPCK: Advances in technological pedagogical content knowledge (TPCK). Computers \& Education 52, no. 1: 154-68.

Bottino, R.M. 2004. The evolution of ICT-based learning environments: Which perspectives for the school of the future? British Journal of Educational Technology 35, no. 5: 553-67.

Carvalho, L., A. Dong, and K. Maton. 2009. Legitimating design: A sociology of knowledge account of the field. Design Studies 30, no. 5: 483-502.

Chen, R., K. Maton, and S. Bennett. 2011. Absenting discipline: Constructivist approaches in online learning. In Disciplinarity: Systemic functional and sociological perspectives, ed. F. Christie and K. Maton, 129-50. London: Continuum.

Christie, F., and M. Macken-Horarik. 2011. Disciplinarity and school subject English. In Disciplinarity: Systemic functional and sociological perspectives, ed. F. Christie and K. Maton, 175-96. London: Continuum.

Czerniewicz, L. 2008. Distinguishing the field of educational technology. Electronic Journal of e-Learning 6, no. 3: 171-8.

Czerniewicz, L. 2010. Educational technology - Mapping the terrain with Bernstein as cartographer. Journal of Computer Assisted Learning 26, no. 6: 523-34.

Department of Education Employment and Workplace Relations. 2008. Digital Education Revolution. http://www.deewr.gov.au/Schooling/DigitalEducationRevolution/ Pages/default.aspx.

Flick, U. 2006. An introduction to qualitative research. 2nd ed. Thousand Oaks, CA: SAGE Publications.

Freebody, P., K. Maton, and J. Martin. 2008. Talk, text and knowledge in cumulative, integrated learning: A response to 'intellectual challenge'. Australian Journal of Language and Literacy 31: 188-201.

Hennessy, S., K. Ruthven, and S. Brindley. 2005. Teacher perspectives on integrating ICT into subject teaching: Commitment, constraints, caution, and change. Journal of Curriculum Studies 37, no. 2: 155-92.

Hew, K.F., and T. Brush. 2007. Integrating technology into $\mathrm{K}-12$ teaching and learning: Current knowledge gaps and recommendations for future research. Educational Technology Research and Development 55: 223-52.

Howard, S. 2009. Teacher change: Individual and cultural risk perceptions in the context of ICT integration. PhD Diss., University of Sydney.

International Association for the Evaluation of Educational Achievement. 2005. SITES 2006 in brief: Outline. http://www.sites2006.net/exponent/index.php?section=12.

Koehler, M.J., P. Mishra, and K. Yahya. 2007. Tracing the development of teacher knowledge in a design seminar: Integrating content, pedagogy and technology. Computers \& Education 49, no. 3: 740-62.

Lamont, A., and K. Maton. 2008. Choosing music: Exploratory studies into the low uptake of music GCSE. British Journal of Music Education 25, no. 3: 267-82. 
Lamont, A., and K. Maton. 2010. Unpopular music: Beliefs and behaviours towards music in education. In Sociology and music education, ed. R. Wright, 63-80. London: Ashgate.

Law, N., W.J. Pelgrum, and T. Plomp, eds. 2008. Pedagogy and ICT use in schools around the world: Findings from the IEA SITES 2006 study. Hong Kong: CERC-Springer.

Lewin, K. 1951. Field theory in social science. New York: Harper \& Row.

Maton, K. 2000. Languages of legitimation: The structuring significance for intellectual fields of strategic knowledge claims. British Journal of Sociology of Education 21, no. 2: $147-67$.

Maton, K. 2007. Knowledge-knower structures in intellectual and educational fields. In Language, knowledge and pedagogy, ed. F. Christie and J. Martin, 87-108. London: Continuum.

Maton, K. 2010. Progress and canons in the arts and humanities: Knowers and gazes. In Social realism, knowledge and the sociology of education, ed. K. Maton and R. Moore, 154-78. London: Continuum.

Maton, K. Forthcoming. Knowledge and knowers: Towards a realist sociology of education. London: Routledge.

Maton, K., S. Hood, and S. Shay, eds. Forthcoming. Knowledge-building: Educational studies in Legitimation Code Theory. London: Routledge.

Maton, K., and R. Moore, eds. 2010. Social realism, knowledge and the sociology of education. London: Continuum.

Mishra, P., and M.J. Koehler. 2006. Technological pedagogical content knowledge: A framework for teacher knowledge. Teachers College Record 108, no. 6: 1017-54.

Moore, R. 2009. Towards the sociology of truth. London: Continuum.

Moore, R., and K. Maton. 2001. Founding the sociology of knowledge: Basil Bernstein, intellectual fields and the epistemic device. In Towards a sociology of pedagogy, ed. A. Morais, I. Neves, B. Davies, and H. Daniels, 153-82. New York: Peter Lang.

Mueller, J., E. Wood, T. Willoughby, C. Ross, and J. Specht. 2008. Identifying discriminating variables between teachers who fully integrate computers and teachers with limited integration. Computers \& Education 51, no. 4: 1523-37.

Muller, J. 2000. Reclaiming knowledge. London: RoutledgeFalmer.

Muijs, D., J. Campbell, L. Kyriakides, and W. Robinson. 2005. Making the case for differentiated teacher effectiveness: An overview of research in four key areas. School Effectiveness and School Improvement 16, no. 1: 51-70.

Plomp, T., W.J. Pelgrum, and R. Carstens. 2009. Technical overview of SITES 2006. In Second information technology in education study: SITES 2006 technical report, ed. R. Carstens and W.J. Pelgrum, 11-6. Amsterdam: International Association for the Evaluation of Educational Achievement.

Professional Learning and Leadership Development Directorate. 2010a. Digital Education Revolution NSW: Pedagogy. https://www.det.nsw.edu.au/proflearn/der/staffdev/pedagogy. html.

Professional Learning and Leadership Development Directorate. 2010b. Digital Education Revolution NSW: Change. https://www.det.nsw.edu.au/proflearn/der/staffdev/change.html.

Scardamalia, M., and C. Bereiter. 2006. Knowledge building: Theory, pedagogy, and technology. In Cambridge handbook of the learning sciences, ed. K. Sawyer, 97-118. New York: Cambridge University Press.

Scheuermann, F., and F. Pedró, eds. 2010. Assessing the effects of ICT in education: Indicators, criteria and benchmarks for international comparisons. Luxembourg: Centre for Educational Research and Innovation.

Shulman, L. 1987. Knowledge and teaching: Foundations of the new reform. Harvard Educational Review 57, no. 1: 1-23.

Warschauer, M., and T. Matuchniak. 2010. New technology and digital worlds: Analyzing evidence of equity in access, use, and outcomes. Review of Research in Education 34, no. 1: 179-225.

Young, M.F.D. 2008. Bringing knowledge back in. London: Routledge. 